\title{
Short communication: Immunoglobulin variation in quarter-milked colostrum
}

\author{
Craig R. Baumrucker, ${ }^{* 1}$ Andrea Stark, $\dagger$ Olga Wellnitz, $\dagger$ Chad Dechow, ${ }^{*}$ and Rupert M. Bruckmaiert ${ }^{2}$ \\ *Department of Animal Science, Penn State University, University Park, PA 16802 \\ †Veterinary Physiology, Vetsuisse Faculty, University of Bern, CH-3001 Bern, Switzerland
}

\begin{abstract}
Whereas whole first-milked colostrum $\operatorname{IgG}_{1}$ variation is documented, the $\operatorname{IgG}_{1}$ difference between the quarter mammary glands of dairy animals is unknown. First colostrum was quarter-collected from healthy udders of 8 multiparous dairy cows, all within $3 \mathrm{~h}$ of parturition. Weight of colostrum produced by individual quarters was determined and a sample of each was frozen for subsequent analysis. Immunoglobulin $\mathrm{G}_{1}$ concentration $(\mathrm{mg} / \mathrm{mL})$ was measured by ELISA and total mass (g) was calculated. Standard addition method was used to overcome colostrum matrix effects and validate the standard ELISA measures. Analysis of the data showed that cow and quarter (cow) were significantly different in both concentration and total mass per quarter. Analysis of the mean $\mathrm{IgG}_{1}$ concentration of the front and rear quarters showed that this was not different, but the large variation in individual quarters confounds the analysis. This quarter difference finding indicates that each mammary gland develops a different capacity to accumulate precolostrum $\operatorname{IgG}_{1}$, whereas the circulating hormone concentrations that induce colostrogenesis reach the 4 glands similarly. This finding also shows that the variation in quarter colostrum production is a contributor to the vast variation in first milking colostrum $\mathrm{IgG}_{1}$ content. Finally, the data suggests other factors, such as locally acting autocrine or paracrine, epigenetic, or stochasticity, in gene regulation mechanisms may impinge on colostrogenesis capacity.
\end{abstract}

Key words: quarter colostrum, immunoglobulin G, variation

\section{Short Communication}

The importance of adequate passive transfer (APT) of colostrum immunoglobulin to the newborn for minimizing morbidity and mortality has been demonstrated in multiple studies (Quigley et al., 1995; Donovan et al., 1998; Weaver et al., 2000). Although the health

Received June 7, 2013.

Accepted February 12, 2014.

${ }^{1}$ Sabbatical leave with Vetsuisse Faculty.

${ }^{2}$ Corresponding author: Rupert.bruckmaier@vetsuisse.unibe.ch benefits of APT are clear, the reality of calf rearing is that a high proportion of calves on ranches and dairies are deprived of an adequate mass of immunoglobulins, leading to failure of passive transfer (Gay et al., 1983; Lorenz et al., 2011). Calves with APT immunity have lower mortality and morbidity and fewer antibiotic treatments compared with animals with failure of passive transfer (Uetake et al., 2013).

Failure of passive transfer is reported to be $19 \%$ in US dairy heifer calves (Beam et al., 2009), and part of this problem is attributed to feeding colostrum with a low immunoglobulin concentration $(<50 \mathrm{mg} / \mathrm{mL}$ of $\operatorname{IgG}$ ) or feeding an inadequate volume of colostrum with low colostrum IgG concentration (Weaver et al., 2000; Godden, 2008). The concentrations of $\operatorname{IgG}_{1}$ and $\operatorname{IgG}_{2}$ in serum of dairy cows are approximately equal, at $\sim 5$ to 12 $\mathrm{mg} / \mathrm{mL}$, but colostrum shows a very selective mammary transfer of $\mathrm{IgG}_{1}$ accounting for up to a $\sim 10$-fold enhancement (Sordillo et al., 1987). However, cow colostrum has extremely high animal to animal variation in $\operatorname{IgG}_{1}$ concentration (Morin et al., 1997; Quigley et al., 2001). Kehoe et al. (2007) showed IgG concentration varying from 11.8 to $74.2 \mathrm{mg} / \mathrm{mL}$ and Baumrucker et al. (2010) described the mass variation $(30 \mathrm{~g}$ to $>2 \mathrm{~kg}$ ). The current explanation of this variation could be any number of factors, including endocrine (Casey and Plaut, 2007), genetics (Doleschall et al., 2005; Mayer et al., 2005), lactation number, breed of cow, length of the nonlactating period (Pritchett et al., 1991; Tomkins and Jaster, 1991; Weaver et al., 2000; Mansfeld et al., 2012), and the method of analysis (Li-Chan and Kummer, 1997).

Still another source of the variation has been attributed to the time of first milking following parturition. Copious quantities of mature milk components appear en masse following parturition, and with delayed colostrum milking and the inclusion of osmotic molecules, such as lactose and ions, begin to facilitate more water that has a diluting effect on $\operatorname{IgG}_{1}$ concentration. Thus, such water inclusion induces potential variation in each animal colostrum sample when measured as concentration, but would not be expected to affect colostrum total mass of $\operatorname{IgG}_{1}$. Thus, we have affirmed that total mass of $\operatorname{IgG}_{1}$ transferred by a mammary gland would be independent of water influx and more useful in establishing animal variation in transport capacity and, 
perhaps, transport mechanisms that are present during dairy cow colostrogenesis (Baumrucker et al., 2010).

Whereas total colostrum IgG variation in concentration and mass is recognized, the variation within animal quarter is not established. Quarter samples of immunoglobulins taken on the same day pre- and postparturition were reported to vary widely (Kiddy et al., 1971), but no values were provided. We hypothesized that quarter mass production of $\operatorname{IgG}_{1}$ within a cow would not be different. The objective of this study was to (1) establish and validate an ELISA method for analysis of colostrum IgG and (2) determine the udder quarter variation of $\operatorname{IgG}_{1}$ concentration and mass in first-milked colostrum.

\section{Animals}

Eight dairy cows of Holstein Friesian and Swiss Fleckvieh breed with approximately $80 \%$ Red Holstein genes were evaluated. All cows were in their second or third parity from the Agroscope Liebefeld-Posieux research station (Posieux, Switzerland) and were milked within $3 \mathrm{~h}$ of parturition without calf suckling. All quarters were free of mastitis events during the collection period. In the prescribed experiment, each quarter's milk volume was completely collected in a separate bucket by a quarter milking machine based on a Surge RX quarter milking claw (GEA, Böhnen, Germany). The machine teat cups were applied and withdrawn by hand. Each bucket was weighed separately and recorded and a $50-\mathrm{mL}$ aliquot was stored at $-20^{\circ} \mathrm{C}$ until subsequent analysis. Mastitis treatment by quarter (cow) was obtained from the Agroscope Liebefeld-Posieux station veterinary records.

\section{$\lg G_{1}$ Analysis}

Immunoglobulin $\mathrm{G}_{1}$ was measured by an ELISA according to manufacturer's protocol (ELISA Quantitation Set; Bethyl Laboratories Inc., LuBioScience, Luzern, Switzerland), except that the blocking solution was exchanged with a solution made out of twicedistilled water and fish gelatin $[1 \mathrm{~mL}$ of cold water fish skin gelatin (G7765; Sigma Aldrich, Steinheim, Germany) per $20 \mathrm{~mL}$ of twice-distilled water]. The colostrum fractions for this assay were diluted in 1:10 sequential series with the final in plate dilutions of $1 \times 10^{5}, 4$ $\times 10^{5}, 8 \times 10^{5}$, and $1.6 \times 10^{6}$. This was performed because the range of $\operatorname{IgG}_{1}$ content is extremely variable between animals and extensive dilutions are required to overcome matrix effects. The described dilutions of the colostrum were assayed and a mean and SD was obtained that reflected in-plate analysis error. Sample analysis was considered acceptable if in-plate dilutions resulted in concentrations with $\mathrm{CV}$ of $<12 \%$. If the $\mathrm{CV}$ was exceeded, the samples were reanalyzed with suitable dilutions. Interassay repeatability was $<16 \% \mathrm{CV}$.

\section{Standard Addition Method}

The assay of complex mixtures of components, such as bovine colostrum, can be a problem with interpolating from a standard curve because the unknown sample may contain other substances that interfere with the assay. Dilutions of a colostrum sample determined by an ELISA assay, such as the Bethyl IgG assay described previously, will result in increasing concentration of IgG with increasing dilution due to the reduction of interfering substances. This is known as the matrix effect problem. However, at high dilutions, the matrix effect is reduced or eliminated and the diluted samples come to equivalency. The standard addition method (SAM) is a way to overcome this problem. In the SAM procedure, the unknown concentrations are not established by a separate standard cure. Instead, various known concentrations (including zero) of the standard are added to a constant amount of diluted unknown. This ensures that all the samples have the same amount of unknown, including any substances that interfere with the assay.

To test the matrix effect of bovine colostrum, we used SAM to circumvent matrix effects and validate our procedure for the ELISA dilution assay. Standard addition method requires a linear analytical response to dilutions of the sample. However, the typical ELISA standard curve for $\operatorname{IgG}_{1}$ in colostrum is a sigmoid curve. Nevertheless, the lower range of the $\operatorname{IgG}_{1}$ standard curve is linear (lower 3-4 values). Therefore, we used this linear component of colostrum analysis and conducted the SAM with colostrum samples of high to mid concentrations of $\operatorname{IgG}_{1}$ that were established by the ELISA analysis described previously. Figure 1 shows the results of this method with 1 sample of a relatively high concentration of $\operatorname{IgG}_{1}$ that was determined by ELISA to be a mean and $\mathrm{SD}$ of $96.3 \pm 9.5 \mathrm{mg} / \mathrm{mL}$ of $\mathrm{IgG}_{1}$ with a $\mathrm{CV}$ of $8.8 \%$. Figure 1 shows the relatively high $\operatorname{IgG}_{1}$ concentration sample with extrapolated concentrations adjusted for dilution of 93.4, 96.0,90.8, and $94.7 \mathrm{mg} /$ $\mathrm{mL}$ for the 4 dilutions of colostrum. The standard extrapolates to zero. This analysis resulted in a mean of $93.7 \pm 2.1 \mathrm{mg} / \mathrm{mL}$ of $\mathrm{IgG}_{1}$ with a CV of $2.3 \%$. The colostrum medium range concentration sample produced similar results with a CV of $6.8 \%$ when compared with the ELISA assay results (data not shown).

\section{Statistics}

Immunoglobulin $\mathrm{G}_{1}$ mass and concentration established by the ELISA assay were averaged across the 4 


\section{Colostrum with Standard Addition}
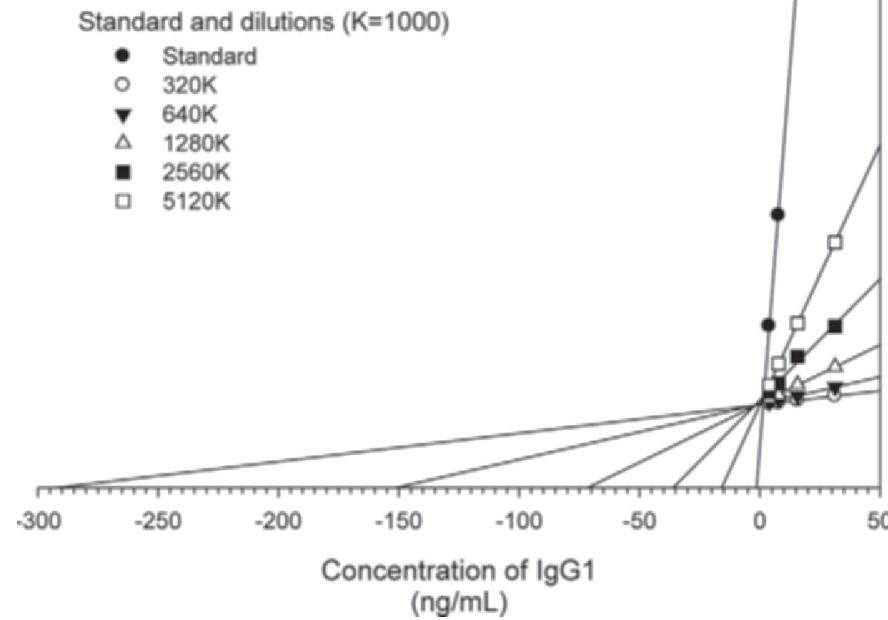

Figure 1. Standard addition method plot utilizing a first-milked colostrum sample. Our ELISA procedure (methods) quantified the $\mathrm{IgG}_{1}$ as $96.3 \pm 8.5 \mathrm{mg} / \mathrm{mL}$. The $\mathrm{y}$-axis is not shown, but is typically the response factor (absorption in plate reader). Extrapolation to the $\mathrm{x}$-axis resulted in the negative values that represent the positive concentration of the diluted sample. When each dilution factor was calculated with the $\mathrm{X}$ value it produced the mean of $93.4 \pm 2.1$ for the 5 diluted samples.

dilutions for each quarter of each cow. This resulted in 32 total observations for $\mathrm{IgG}_{1}$ mass and concentration that were then evaluated with the MIXED procedure of SAS (SAS Institute Inc., Cary, NC). Cow was included as a fixed effect with the denominator degrees of freedom determined using the Satterthwaite approximation $(\mathrm{ddfm}=\mathrm{sat})$ for significance testing. A repeated statement with the group option set to cow was included to fit a separate residual variance for each cow. Akaike's information criterion (AIC), corrected AIC (AICC), and Bayesian information criterion (BIC) were then compared among models with and without the repeated line to evaluate whether significant evidence of heterogeneous variance existed among cows. Attempts to fit mixed models that included effects for both cow and udder half (front vs. rear) did not converge. Therefore, an ANOVA model that included the fixed effects of cow, half, and half within cow was evaluated using the GLM procedure of SAS. This model assumed homogenous variance across all cows.

\section{Results}

Utilization of the SAM (Figure 1) for quantification of $\mathrm{IgG}_{1}$ concentration in first-milked colostrum showed a mean value of $93.4 \mathrm{mg} / \mathrm{mL}$ for the 5 diluted samples with a CV of $2 \%$. This mean value agrees with the
ELISA values of $96.3 \mathrm{mg} / \mathrm{mL}$ for the 4 in-plate dilutions conducted on the same sample. This finding confirms that extensive dilution of the colostrum sample reduces the matrix effect of colostrum in the standard ELISA assay, as described in our methods, so as to reach an accurate estimate of $\operatorname{IgG}_{1}$ concentration. Such dilutions may exceed $1 \times 10^{6}$ for highly concentrated IgG colostrum samples.

Both the mixed and ANOVA models confirmed that cow had a significant effect on $\operatorname{IgG}_{1}$ mass and concentration. Additionally, fitting a heterogeneous variance structure improved fit statistics (AIC, AICC, BIC) for the evaluation for $\operatorname{IgG}_{1}$ concentration, which indicated that the amount of variation among quarters was different among cows. Fitting a heterogeneous variance structure also improved the model fit for $\operatorname{IgG}_{1}$ mass according to AIC and AICC, but not for BIC. Figure 2 shows the results of $\operatorname{IgG}_{1}$ concentration and mass collected by quarter from 8 individual cows. The columns correspond to the average of the 4 dilutions for $\mathrm{IgG}_{1}$ mass or concentration with lines that indicate the standard deviation among the dilutions. The relatively small lines demonstrate that the dilutions resulted in repeatable results for each cow. Within each animal figure is printed the residual (R) from the heterogeneous variance analysis. Figure 2 indicates that $\operatorname{IgG}_{1}$ concentration varied minimally among quarters for 4 cows $(1601,1609,1627$, and 1695) as indicated by the low $\mathrm{R}$. Also, $\operatorname{IgG}_{1}$ mass varied minimally among quarters for cows 1601, 1609, and 1695, as shown by their low R. It is notable that mass R for cow 1627 is high, whereas the concentration $\mathrm{R}$ is low.

Figure 2 also indicates that $\operatorname{IgG}_{1}$ concentration was highly varied among quarters for cows 1296, 1530, and 1685 , as shown by their high $R$. Similarly, $\operatorname{IgG}_{1}$ mass was highly varied among quarters for cows 1296, 1530, 1627, 1640, and 1685, as indicated by their high $\mathrm{R}$.

Finally, we tested front against rear quarters for differences in concentration and mass of $\mathrm{IgG}_{1}$. No significant differences were observed between udder halves for the ANOVA analyses. Figure 3 shows the variation between front and rear quarters of the experimental cows. The LSMEANS for $\operatorname{IgG}_{1}$ concentration were 52.4 and $46.1 \mathrm{mg} / \mathrm{mL}$ for front and rear udder halves, respectively. The mass of $\mathrm{IgG}_{1}$ exhibited LSMEANS of 86.5 and $104.6 \mathrm{~g}$ for the front and rear udder halves, respectively. The analysis indicated that $\operatorname{cow}(P=$ $0.0003)$ was significant whereas udder half $(P=0.30)$ and udder half within cow $(P=0.65)$ were not significant. Three cows $(1296,1640$, and 1685) showed large mean differences in mass of $\mathrm{IgG}_{1}$ between the front and rear quarters, and the quarter variation shown in Figure 2 is very large so as to produce a statistical test that is nonsignificant. 


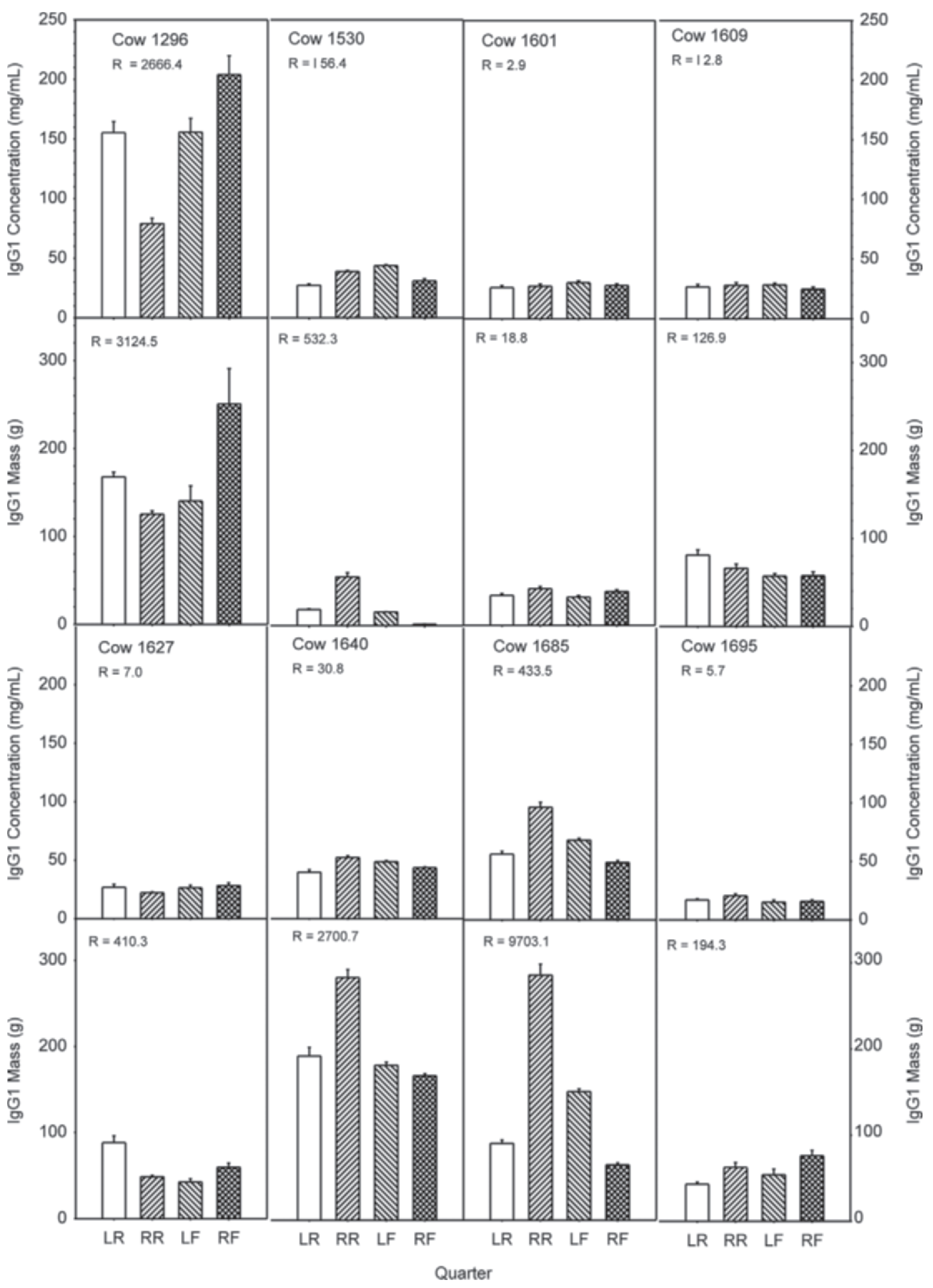

Figure 2. Immunoglobulin $\mathrm{G}_{1}$ colostrum concentration and mass in first-milked quarters. Data are the mean of concentration and mass of $\mathrm{IgG}_{1}$ for individual cows and their quarters. Also shown for each quarter is the residual ( $\mathrm{R}$ ) from the heterogeneous model described in Materials and Methods. The error bars indicate the SD of for each quarter among in-plate dilutions. $\mathrm{LR}=$ left rear, $\mathrm{RR}=\mathrm{right}$ rear, $\mathrm{LF}=\mathrm{left}$ front, $\mathrm{RF}$ $=$ right front. 


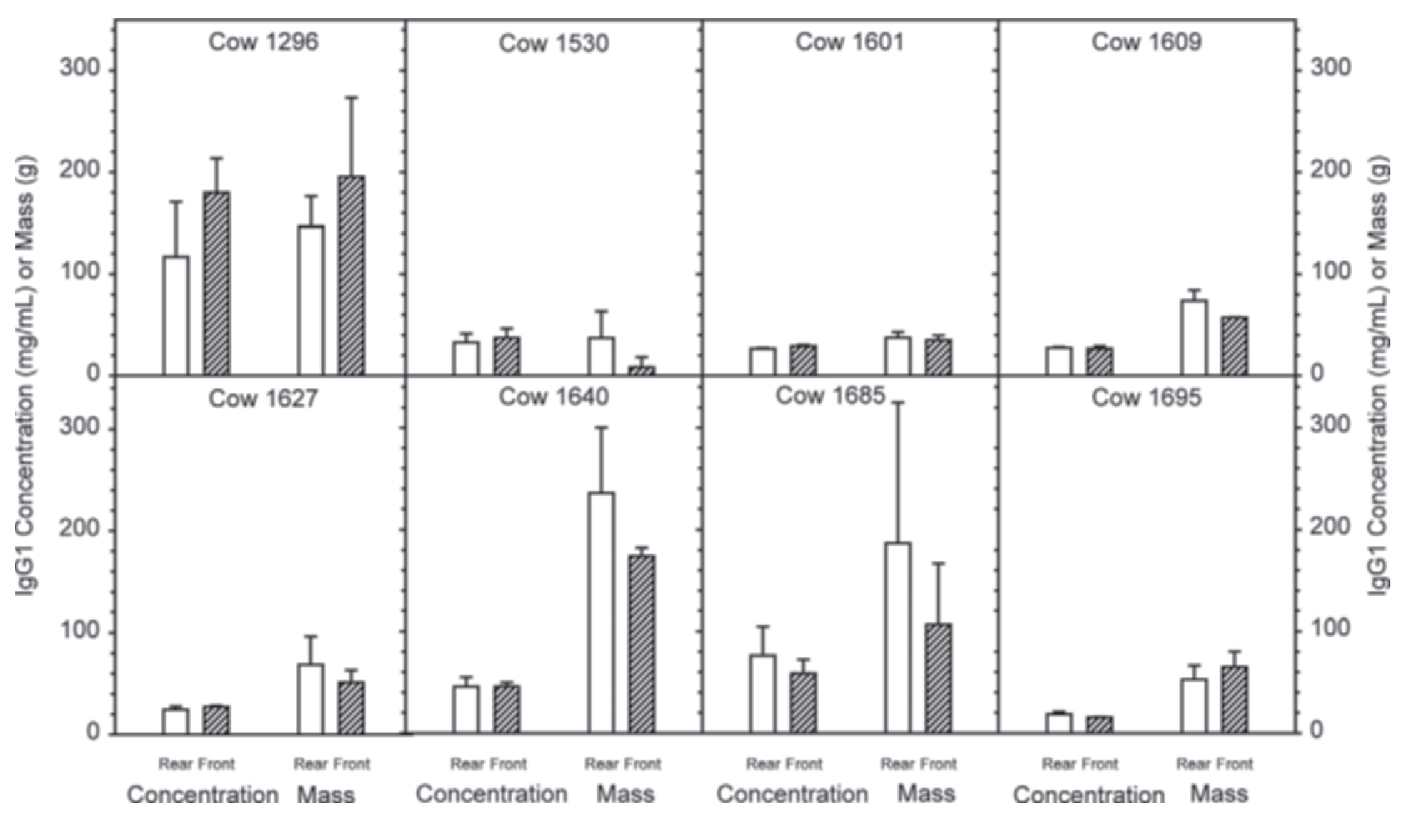

Figure 3. Immunoglobulin $\mathrm{G}_{1}$ colostrum concentration and mass in first-milked front and rear quarters. Data are the mean \pm SD of either concentration or mass of $\operatorname{IgG}_{1}$ for each cow front and rear quarters. Analysis indicated that cow $(P=0.0003)$ was significant, whereas udder half $(P=0.30)$ and udder half within cow $(P=0.65)$ were nonsignificant.

\section{Discussion}

The use of SAM allows for the control of matrix effects if the analytical output produces a linear result. Whereas most ELISA results are sigmoid curves, the lower range of detection is linear. We used these values to show that the standard addition method applied to highly diluted bovine first milk colostrum results in a concentration that was equivalent to our standard ELISA assay. These results validate the use of the ELISA we describe in the methods to quantify $\operatorname{IgG}_{1}$ in bovine colostrum.

The concentration and mass of $\operatorname{IgG}_{1}$ in first colostrum of cows has been shown to be vastly different between cows and not related to the mass of parenchyma tissue (Baumrucker et al., 2010; Kehoe et al., 2007). A recent report by Kessler et al. (2013) provides more evidence of the disconnect between mature milk secretion volume and colostrum volume. Furthermore, whereas concentration and mass of $\mathrm{IgG}_{1}$ in first-milked colostrum are related $\left(\mathrm{R}^{2} \sim 0.65\right.$; Baumrucker et al., 2010) within an animal, they can be significantly different. An animal that has higher concentration is more likely to produce greater mass, but a lower concentration of colostrum can achieve greater mass by the production of high volume (mass $=$ concentration $\times$ volume). One explanation for the concentration difference between animals is the variation in the timing of the beginning of differentiation from colostrum formation and that of copious mature milk production. This process has been described as the change from lactogenesis I (proliferation, differentiation, and colostrogenesis) to lactogenesis II (natural milk production; Nguyen and Neville, 1998) and begins to occur days before parturition. Each cow may begin the process at different times, which results in the formation of mature milk production that includes more lactose and ions resulting in increased water content added to the preformed colostrum, thereby diluting $\operatorname{IgG}_{1}$ concentration at first milking. Furthermore, if quarters develop at different rates from lactogenesis I into the lactogenesis II stage, then concentration differences could be explained. Nevertheless, no current data supports mammary quarter differential development within an animal.

Whereas this explanation may explain concentration variation between the cow mammary gland quarters, water inclusion has little or no effect upon total mass produced by a quarter of the mammary gland. It was therefore surprising to find that quarter (cow) mass was different. We therefore reject our initial hypothesis that quarter mass production of $\operatorname{IgG}_{1}$ within a cow would not be different.

Different quarters are known to produce different volumes of milk during an established lactation, with the rear quarters generally producing more milk volume due to the greater mass of parenchyma tissue (Tucker, 1981). In our analysis, the front quarters produced colostrum with higher $\operatorname{IgG}_{1}$ concentration when compared with the rear quarters (52 vs. $46 \mathrm{mg} / \mathrm{mL}$ ). This may be explained by the greater dilution effect occurring by 
secretory activation (lactogenesis II) in these rear quarters with more secretory tissue. In support of this idea, mass was greater in the rear quarters (104 vs. $86 \mathrm{mg}$ / $\mathrm{mL}$ ), suggesting the rear location has some relevance to $\operatorname{IgG}_{1}$ transcytosis. However, referring back to Figure 2 , it is clear that the averaging of some quarters with extreme differences (variation) to produce a mean for an udder half does not provide a clear answer to the question of $\operatorname{IgG}_{1}$ production.

Anatomical studies have clearly shown that a cow's udder is divided into 4 separate quarters (Hammond, 1927). Many experimental paradigms have used this knowledge to test one quarter while utilizing another for a control (i.e., mastitis experiments with lipopolysaccharide). It is also known that the steroid hormones released from the conceptus during pregnancy and involved in the initiation of colostrogenesis result in increases in the blood concentrations and that each separate quarter of the cow mammary gland would be exposed to a very similar concentration of these hormones (Guy et al., 1994). Our findings show that any quarter within a cow udder may produce different concentrations and mass of $\operatorname{IgG}_{1}$ in the first-milked colostrum that appears to be unrelated to parenchyma tissue; this is supported by previous findings with total colostrum (Baumrucker et al., 2010). An extremely low total mass production in first-milked colostrum of any cow would clearly indicate that all quarters are rather poor in the transcytosis of $\operatorname{IgG}_{1}$ from the blood to the secretions, whereas an extremely high-quality colostrum producer would likely have all quarters functioning extremely well in $\operatorname{IgG}_{1}$ mass transfer. Those animals with average transfer of mass could be illustrated by cow 1685 (Figure 2). Clearly, the quarter variation in colostrum formation is a major contributor of the variation in first-milked colostrum $\operatorname{IgG}_{1}$ content (Baumrucker et al., 2010).

It is known that though each mammary gland is independent, the lactating tissue is developed from the same general copies of DNA from preexisting mammary epithelial cells. Previous lactation cell numbers that remain for the subsequent lactation may be contributors to this variation. Such variation may be resolved by testing first lactation animals, and we are in the process of such experiments. However, genetic contribution to this quarter variation cannot be explained unless epigenetic mechanisms (Rijnkels et al., 2013) are contributing to colostrogenesis and are influenced independently within each quarter. Perhaps, stochasticity in gene expression (Kaern et al., 2005) may also be included in the list of unknown regulatory factors. Still another explanation may be the effect of differential expression of local factors, paracrine or autocrine, which contribute to the colostrogenesis mechanisms induced by steroids (Guy et al., 1994). However, quarter differential expression of these and other factors within the same animal is currently undocumented. It is also possible that previous mammary quarter disease problems (mastitis) contribute to this variation. The latter explanation may account for necrotic damage to mammary epithelium and could also result in independent epigenetic control of separate quarters. However, necrotic damage would lead to less productive parenchymal tissue and our previous work suggested that colostrum production was not related to parenchymal tissue mass (Baumrucker et al., 2010); a new report (Kessler et al., 2014) indicates no relationship between colostrum volume and subsequent milk volume within an animal. We had limited quarter disease information for the cows described in the current research and our sample size was too limiting; thus, no conclusion could be reached. More research is needed to shed light on the factors that control this process.

Finally, our findings about colostrogenesis in the mammary glands of cows indicate that the sampling of fluid or tissue from one mammary gland for analysis of colostrogenesis may not reflect the process occurring in the other quarters of the udder. It would be interesting to know if this is also occurring in other species of mammals.

\section{REFERENCES}

Baumrucker, C. R., A. M. Burkett, A. L. Magliaro-Macrina, and C. D. Dechow. 2010. Colostrogenesis: Mass transfer of immunoglobulin $\mathrm{G}_{1}$ into colostrum. J. Dairy Sci. 93:3031-3038.

Beam, A. L., J. E. Lombard, C. A. Kopral, L. P. Garber, A. L. Winter, J. A. Hicks, and J. L. Schlater. 2009. Prevalence of failure of passive transfer of immunity in newborn heifer calves and associated management practices on US dairy operations. J. Dairy Sci. 92:3973-3980.

Casey, T. M., and K. Plaut. 2007. The role of glucocorticoids in secretory activation and milk secretion, a historical perspective. J. Mammary Gland Biol. Neoplasia 12:293-304.

Doleschall, M., Y. Zhao, B. Mayer, L. Hammarstrom, and I. Kacskovics. 2005. Isolation of the gene encoding the bovine neonatal Fc receptor. Vet. Immunol. Immunopathol. 108:145-150.

Donovan, G. A., I. R. Dohoo, D. M. Montgomery, and F. L. Bennett. 1998. Associations between passive immunity and morbidity and mortality in dairy heifers in Florida, USA. Prev. Vet. Med. 34:31-46.

Gay, C. C., T. C. McGuire, and S. M. Parish. 1983. Seasonal variation in passive transfer of immunoglobulin G1 to newborn calves. J. Am. Vet. Med. Assoc. 183:566-568.

Godden, S. 2008. Colostrum management for dairy calves. Vet. Clin. North Am. Food Anim. Pract. 24:19-39.

Guy, M. A., T. B. McFadden, D. C. Cockrell, and T. E. Besser. 1994. Regulation of colostrum formation in beef and dairy cows. J. Dairy Sci. 77:3002-3007.

Hammond, J. 1927. The Physiology of Reproduction in the Cow. Cambridge University Press, Cambridge, UK.

Kaern, M., T. Elston, W. Blake, and J. Collins. 2005. Stochasticity in gene expression: From theories to phenotypes. Nat. Rev. Genet. 6:451-464.

Kehoe, S. I., B. M. Jayarao, and A. J. Heinrichs. 2007. A survey of bovine colostrum composition and colostrum management practices on Pennsylvania dairy farms. J. Dairy Sci. 90:4108-4116. 
Kessler, E., R. M. Bruckmaier, and J. J. Gross. 2013. Milk production during the colostral period is not related to the later production level in dairy cows. J. Dairy Sci. 96(E-Suppl. 1):145. (Abstr.)

Kessler, E. C., R. M. Bruckmaier, and J. J. Gross. 2014. Milk production during the colostral period is not related to the later lactational performance in dairy cows. J. Dairy Sci. 97:2186-2192. http://dx.doi.org/10.3168/jds.2013-7573.

Kiddy, C. A., R. McCann, C. Maxwell, C. Rock, C. Pierce, and J. E. Butler. 1971. Changes in levels of immunoglobulin in serum and other body fluids immediately before and after parturition. J. Dairy Sci. 54:1325-1327.

Li-Chan, E. C. Y., and A. Kummer. 1997. Influence of standard and antibodies in immunochemical assays for quantitation of immunoglobulin G in bovine milk. J. Dairy Sci. 80:1038-1046.

Lorenz, I., J. F. Mee, B. Earley, and S. J. More. 2011. Calf health from birth to weaning. I. General aspects of disease prevention. Ir. Vet. J. $64: 10$.

Mansfeld, R., C. Sauter-Louis, and R. Martin. 2012. Effects of dry period length on milk production, health, fertility, and quality of colostrum in dairy cows. Invited review. Tierarztl. Prax. Ausg. G Grosstiere Nutztiere 40:239-250.

Mayer, B., M. Doleschall, B. Bender, J. Bartyik, Z. Bosze, L. V. Frenyo, and I. Kacskovics. 2005. Expression of the neonatal Fc receptor $(\mathrm{FcRn})$ in the bovine mammary gland. J. Dairy Res. 72(Spec. No.):107-112.

Morin, D. E., G. C. McCoy, and W. L. Hurley. 1997. Effects of quality, quantity, and timing of colostrum feeding and addition of a dried colostrum supplement on immunoglobulin $\mathrm{G}_{1}$ absorption in Holstein bull calves. J. Dairy Sci. 80:747-753.

Nguyen, D. A., and M. C. Neville. 1998. Tight junction regulation in the mammary gland. J. Mammary Gland Biol. Neoplasia 3:233246.
Pritchett, L. C., C. C. Gay, T. E. Besser, and D. D. Hancock. 1991 Management and production factors influencing immunoglobulin $\mathrm{G}_{1}$ concentration in colostrums from Holstein cows. J. Dairy Sci. $74: 2336-2341$.

Quigley, J. D., III, K. R. Martin, D. A. Bemis, L. N. Potgieter, C. R. Reinemeyer, B. W. Rohrbach, H. H. Dowlen, and K. C. Lamar. 1995. Effects of housing and colostrum feeding on serum immunoglobulins, growth, and fecal scores of Jersey calves. J. Dairy Sci. 78:893-901.

Quigley, J. D., R. E. Strohbehn, C. J. Kost, and M. M. O'Brien. 2001. Formulation of colostrum supplements, colostrum replacers and acquisition of passive immunity in neonatal calves. J. Dairy Sci. 84:2059-2065.

Rijnkels, M., C. Freeman-Zadrowski, J. Hernandez, V. Potluri, L. Wang, W. Li, and D. Lemany. 2013. Epigenetic modifications unlock the milk protein gene loci during mouse mammary gland development and differentiation. PLoS ONE 8:1-16.

Sordillo, L. M., S. C. Nickerson, R. M. Akers, and S. P. Oliver. 1987. Secretion composition during bovine mammary involution and the relationship with mastitis. Int. J. Biochem. 19:1165-1172.

Tomkins, T., and E. H. Jaster. 1991. Preruminant calf nutrition. Vet. Clin. North Am. Food Anim. Pract. 7:557-576.

Tucker, H. A. 1981. Physiological control of mammary growth, lactogenesis, and lactation. J. Dairy Sci. 64:1403-1421.

Uetake, K. 2013. Newborn calf welfare: A review focusing on mortality rates. Anim. Sci. J. 84:101-105.

Weaver, D. M., J. W. Tyler, D. C. VanMetre, D. E. Hostetler, and G. M. Barrington. 2000. Passive transfer of colostral immunoglobulins in calves. J. Vet. Intern. Med. 14:569-577. 